\title{
Relationship between adiponectin, obesity and insulin resistance
}

\author{
Guilherme Ardenghi Balsan ${ }^{1}$, José luiz da Costa Vieira² ${ }^{2}$ Aline Marcadenti de Oliveira ${ }^{3}$, Vera Lúcia Portal ${ }^{4 *}$ \\ ${ }^{1}$ Masters in Food Engineering from the Regional Integrated University of Upper Uruguai and Missions - URI Erechim Campus - State of Rio Grande do Sul. Doctorate student in Health Sciences / Cardiology at the \\ Cardiology University Foundation -RS (FUC-RS), Porto Alegre, RS, Brazi \\ ${ }^{2} \mathrm{PhD}$ in Health Sciences (Cardiology) - Coordinator of the Medical Residency Outpatient Clinic at the Institute of Cardiology at FUC-RS, Porto Alegre, RS, Brazil \\ ${ }^{3} \mathrm{PhD}$ in Cardiovasculary Sciences from Ufrgs - Full Professor for the Graduate Program at the Institute of Cardiology at FUC-RS, Porto Alegre, RS, Brazil \\ ${ }^{4} \mathrm{PhD}$ in Health Sciences (Cardiology) - Vice-coordinator of the Graduate Program in Health Sciences at FUC-RS, Porto Alegre, RS, Brazil
}

\begin{abstract}
SUMMARY
Study conducted at Institute of Cardiology of Rio Grande do Sul - Cardiology University Foundation (IC/FUC)

Article received: $3 / 12 / 2014$ Accepted for publication: 6/3/2014

*Correspondence: Address: Avenida Princesa Isabel, 370 Santana

Postal Code: 90620-000

Porto Alegre, RS - Brazil veraportal.pesquisa@gmail.com

http://dx.doi.org/10.1590/1806-9282.61.01.072

Objectives: the conditions of obesity and overweight pose a major risk for a number of comorbidities, including clinical syndromes resulting from atherosclerotic disease. Recent studies strongly indicate that adipose tissue is an active endocrine organ that secretes bioactive factors such as adipokines. Adiponectin appears to have a regulatory role in the mechanism of insulin resistance and in the development of atherosclerosis. This systematic review aims to evaluate the anti-atherogenic effects of adiponectin and its properties to improve and mimic metabolic and vascular actions of insulin and its influence on endothelial function.

Methods: a qualitative, exploratory and literature review was performed in the PubMed, Portal Capes and Scielo databases using as key-words "adiponectin", "obesity", "insulin resistance", "anti-inflammatory", "therapeutic strategies" and "future prospects".

Results: evidence suggests that adiponectin has anti-atherogenic properties with anti-inflammatory effects on the vascular wall. Moreover, it modifies the vascular intracellular signaling and has indirect antioxidant effects on the human myocardium. On the other hand, there are studies suggesting that increased levels of adiponectin are paradoxically associated with a worse prognosis in heart failure syndrome, although the mechanisms are not clear.

Conclusion: it is not clear whether adiponectin levels have any clinical significance for risk stratification in cardiovascular disease or if they simply reflect the activation of complex underlying mechanisms. Changes in lifestyle and some drug treatments for hypertension and coronary heart disease have shown significant effect to increase adiponectin levels, and simultaneously decrease in insulin resistance and endothelial dysfunction.
\end{abstract}

Conflict of interest: none
Keywords: obesity, adiponectin, insulin resistance.

\section{INTRODUCTION}

Obesity is a major public health problem worldwide, with significant social and psychological dimensions that have afflicted increasingly younger individuals and different socioeconomic groups. It is one of the most important determinants of many chronic non-communicable diseases (NCD) that significantly affect the mortality rate of many countries, including developing countries. ${ }^{1}$

The prevalence of obesity (body mass index (BMI) $>30 \mathrm{~kg} / \mathrm{m}^{2}$ ) has increased substantially in recent years and forecasts suggest that if current trends continue, up to $58 \%$ of adults worldwide will be overweight or obese by
2030. Obesity is an independent risk factor for venous thromboembolism and ischemic heart disease, having a negative impact on public health. ${ }^{2}$

Interactions between lifestyle factors (self-determined behaviors acquired socially or culturally, individually or as part of a group, and thus modifiable) and genetic factors (that modulate the body's response to changes in lifestyle factors) are part of this perspective. Therefore, the combination of determinants of obesity and its complications include both lifestyle and genetic factors with different and important contributions. ${ }^{3}$ 
Obesity is a condition in which the number and size of adipocytes increases with further increase of the total fat mass. With industrialization, obesity is advancing along with its association with the risk of diseases such as dyslipidemia, insulin resistance, high blood pressure (HBP), and eventually atherosclerosis or other cardiovascular diseases. Although the risk is well established, the mechanisms leading to it are still unclear. ${ }^{4}$ The pathogenic relationship between obesity, metabolic syndrome, and their cardiovascular complications is well established; however, the mechanisms by which excess body fat causes these conditions need to be clarified. The direct vascular and metabolic effects of plasma proteins that originate from adipose tissue, especially adiponectin, have received growing attention. ${ }^{5}$

The reduction in plasma adiponectin levels observed in patients with type 2 diabetes mellitus (T2DM), metabolic syndrome and coronary artery disease may play a key role in the development of insulin resistance. Even though the mechanisms underlying the anti-inflammatory properties of adiponectin are not well understood, the anti-atherogenic and anti-inflammatory properties of adiponectin may be related in part to its ability to stimulate the production of nitric oxide by the vascular endothelium. ${ }^{6}$

The idea of adipose tissue as a place only for energy storage has changed dramatically in recent years. Adipose tissue is now considered as one large metabolically active compartment involved in the regulation of several biological functions. The communication between adipose tissue and other biological systems is possible through the expression of a large number of bioactive mediators that are collectively called adipokines. Adiponectin is known as an important adipokine and is involved in various biological processes in the human body. The change in the profile of serum adipokines in obese subjects, such as levels of adiponectin and pro-inflammatory cytokines, are proposed as a contributing factor to the development of cardiometabolic alterations. However, in some cases, individuals regarded as obese do not exhibit these changes. ${ }^{4}$

Adiponectin was first described as a peptide of adipose tissue that becomes dysregulated in obesity. Shortly after, its potential as an anti-atherogenic factor was recognized for its ability to modulate the expression of endothelial adhesion molecules and affect key mechanisms involved in atherogenesis. Since then, many experimental and clinical studies have thoroughly examined the role of adiponectin in vascular homeostasis and its potential value as a clinical biomarker in cardiovascular diseases, providing inconsistent results. ${ }^{7}$
Adiponectin, unlike the other substances released by adipose tissues, acts as a protective factor for cardiovascular disease, increases insulin sensitivity and has a beneficial effect on postprandial glucose and lipid metabolism. ${ }^{7}$ Its levels are lower in obese people compared to the non-obese, as well as in individuals identified as insulin resistant; patients with T2DM, high blood pressure and particularly patients with coronary heart disease. ${ }^{8}$

In this review, we discuss the anti-atherogenic effects of adiponectin and its properties to improve and mimic the metabolic and vascular actions of insulin, as well as its influence on endothelial function. Special emphasis is given to issues involving the relationship between adiponectin and both obesity and insulin resistance, as well as prospects for future research and treatment.

\section{Structure AND Secretion of ADiponectin}

Adiponectin is a $30 \mathrm{kDa}$ protein with a C-terminal globular domain and a collagen-like $\mathrm{N}$-terminal domain. The collagen domain allows for trimeric or hexameric formation and other multimeric isoforms before being secreted. A cysteine residue at collagenous rod is an essential mediator of multimeric complexes, which may represent the most biologically active form of the protein. Adiponectin is structurally related to proteins of the complement system $(\mathrm{C} 1 \mathrm{q})$ and tumor necrosis factor alpha (TNF- $\alpha$ ), which are prototype members of a growing family of proteins known as CTRPs (C1q/TNF bonds). ${ }^{9}$

Adiponectin, a product of the APM1 gene, is a protein composed of 244 amino acids, also known as GBP28 (galatin binding protein-28), ADOPOQ and ACRP30. This protein is largely secreted by adipocytes, although it can also be secreted by cardiomyocytes, hepatocytes and placenta at lower concentrations. Its structure is divided into three domains: the N-terminal domain, which has large variation in amino acids between species, the collagen-like domain, and the globular domain of the C-terminal region. ${ }^{10}$

The secretion of adiponectin is strictly controlled by the retention of protein thiols, so that two molecular endoplasmic reticulum chaperones play a critical role: 44 $\mathrm{kDa}$ ER proteins (endoplasmic reticulum protein 44 , ERp44) and Ero1-La (endoplasmic reticulum oxidoreductin 1-like alpha), both induced during adipogenesis. ERp44 forms a disulfide bond with adiponectin, which is important for the maturation of trimeric and hexameric proteins of high-, medium- and low-molecular weight in oligomers. It is also involved in the specific intracellular retention of adiponectin, so that the overexpression of ERp44 reduces the secretion of the adipokine. The Ero1- 
La protein, in turn, is a close partner of ERp44 and is involved in the weakening of the disulfide covalent bond between adiponectin and ERp44 and consequently the release of adiponectin. ${ }^{9}$

\section{BIOSYNTHESIS OF ADIPONECTIN AND RECEPTORS}

Adiponectin is mainly produced from white adipose tissue and specifically in mature adipocytes. Three major adipose tissue deposits are recognized as producers of this protein: subcutaneous, visceral and perivascular. The concentration of circulating adiponectin in plasma is very high ( 2 to $30 \mu \mathrm{g} / \mathrm{mL}$ ). The plasma levels of this protein in the Japanese population is around 5 to $10 \mu \mathrm{g} / \mathrm{mL}$, while in serum it is lower in Indo-Asians compared to Caucasians (median $3.3 v s .4 .9 \mu \mathrm{g} / \mathrm{mL}$ ). Women have circulating adiponectin levels approximately $40 \%$ higher than men.,11

Interestingly, visceral fat compartments are largely responsible for the secretion of adiponectin, when compared to subcutaneous deposits. This is of particular interest because of the close association between visceral obesity and metabolic/cardiovascular disease; however, in vitro and in vivo studies performed in humans have shown that adipocytes with exhausted lipid storage, filled with fatty acids, and located in the intra-abdominal region can inhibit transcription of the adiponectin gene by secreting inflammatory and angiogenic factors, reducing its plasma levels. ${ }^{12}$ The epicardial fat is also a source of adiponectin. Lower levels are also expressed in the liver, cardiomyocytes, skeletal muscle, colon, salivary gland, placenta and hypophysis, but the contributions of these tissues to the circulating adiponectin is considerably small. Adiponectin can also be detected in breast milk and cerebrospinal fluid, although in low concentrations. ${ }^{11}$

The role of adiponectin is mediated by receptors known as adiponectin receptors 1 and 2 (Adipor 1 and Aipor2). These receptors have seven transmembrane portions, but are functionally different from the $G$ proteincoupled receptors, particularly because they have opposite polarity (i.e., the $\mathrm{N}$-terminal faces the intracellular compartment). Although in relative proportions, Adipor1 and Adipor 2 may vary from tissue to tissue and, in general, are expressed simultaneously. ${ }^{13}$ An additional cell surface molecule called T-cadherin shows significant affinity for adiponectin. T-cadherin binds to adiponectin, which is not a signaling receptor due to lack of intracellular signaling domains, to confer full cardioprotective potential to the latter. ${ }^{14}$

Adiponectin works in an autocrine and paracrine manner in the adipose tissue, and in an endocrine manner in distal tissues. The autocrine effects are illustrated by their role in adipocyte differentiation. Induction is greater than 100 times that of adiponectin mRNA during the course of differentiation of adipose cells. ${ }^{14}$ Similarly, in experiments involving adipocytes overexpressing adiponectin, cell differentiation was accelerated, leading to increased lipid accumulation and insulin-stimulated glucose transport activity in fully differentiated cells. Thus, adiponectin promotes adipocyte differentiation and increased insulin sensitivity ${ }^{15,16}$ Also, recent in vivo and in vitro studies provided evidence of a regulatory feedback loop by which adiponectin controls its own production and the expression of its receptor. In addition to the regulatory capacity, adiponectin acts as an autocrine and paracrine factor to inhibit the secretion by adipocytes of interleukins 6 and 8 , macrophage inflammatory protein $1 \alpha / \beta$ and monocyte chemotactic protein- 1 , which, in turn, can inhibit the storage of lipids and insulin sensitivity in adipocytes. ${ }^{16,17}$

Adiponectin can also act as an endocrine factor. It has been shown that adiponectin administration leads to a rise in insulin-stimulated tyrosine phosphorylation of insulin receptors in muscle, both for rodents and humans. ${ }^{18}$ This effect may contribute to the improvement of insulin sensitivity. According to Bacha et al., ${ }^{19}$ adiponectin levels are responsible for $73 \%$ of the variation in insulin sensitivity. ${ }^{19}$

\section{Obesity and adiponectin}

Role of free fatty acids on endothelial dysfunction

Central or abdominal obesity leads to insulin resistance and endothelial dysfunction due to the formation of metabolic products derived from lipids, hormones and cytokines. Additionally, insulin resistance may lead to endothelial dysfunction and changes in the insulin signaling pathway, specific or shared, in muscle tissue, adipose tissue and endothelial cells. New genetic and nontraditional factors may be involved in these mechanisms. Recent clinical studies have shown that pharmacological or nonpharmacological strategies to combat obesity and/or insulin resistance can improve the endothelial dysfunction and mild inflammation seen in these conditions. All these findings have added a new dimension to the association of obesity, insulin resistance and endothelial dysfunction, which may become a key target in the prevention of T2DM and cardiovascular diseases. ${ }^{20}$

The mechanism by which the increase in free fatty acids leads to decreased glucose uptake appears to involve higher levels of intramitochondrial NADH and acetyl CoA. As a result, there is inhibition of phosphofructokinase and hexokinase II, leading to increased intracellular concentration of glucose, as well as uptake. However, oth- 
er authors have different ideas and suggest that the inhibition of glucose transport or phosphorylation activity precedes the reduction in glycogen synthesis and glucose oxidation induced by free fatty acids. ${ }^{21}$

It should be noted that by increasing intracellular metabolites of fatty acids, there may be activation of the serine/threonine kinase cascade, possibly via protein kinase $\mathrm{C}$ delta, leading to the phosphorylation of serine/ threonine in the substrate for the insulin receptor 1 (IRS1). Phosphorylated IRS-1 of serine does not bind or activate phosphatidylinositol 3-kinase (PI-3K), resulting in decreased transport of glucose and other manifestations of insulin resistance. Free fatty acids can also directly affect the expression, transcription or recruitment to the cell surface of the glucose transporter type 4 (Glut-4). In addition, free fatty acids reduce the hepatic clearance of insulin and increase the hepatic production of glucose, both enhancing the effects of insulin resistance. ${ }^{22}$

Plasma levels of adiponectin are decreased significantly in obese patients, and negatively correlated with BMI. People with T2DM have lower plasma adiponectin concentrations compared to non-diabetic individuals, regardless of BMI. In many studies, plasma adiponectin levels were lower in patients with coronary artery disease (CAD) than in controls matched for BMI and age. Hypoadiponectinemia, defined by the $25^{\text {th }}$ percentile, was associated with an increase in 2 times in the prevalence of CAD in males, after accounting for other risk factors. Even in patients with T2DM, those with CAD have lower adiponectin levels than those without CAD. While adiponectin levels are increased in patients with T1DM and terminal kidney disease, hypoadiponectinemia is an independent predictor of cardiovascular events in these patients. ${ }^{22,23}$
In a prospective study, men with high plasma levels of adiponectin without prior CVD had a lower risk of myocardial infarction compared to those with medium or low levels. Among male participants of a cohort, adiponectin was associated in type 2 diabetic patients with a decreased risk of CAD-related events (myocardial infarction and coronary artery bypass grafting), and that was partly due to the effects of adiponectin on HDL cholesterol levels. It is also suggested that lower levels of adiponectin are associated with defects in the catabolism of VLDL-apoB particles, which increases the effect of dyslipidemic insulin-resistance, mainly resulting in increased hepatic production of VLDL-ApoB. ${ }^{24}$

\section{Adiponectin influence on endothelial and vascular function}

During the early stages of atherosclerosis, various lipoproteins such as low density lipoprotein (LDL), are deposited in the intima of the vascular wall. These lipoproteins are closely connected to oxidation and they induce many adhesion molecules on endothelial cells, such as vascular cell adhesion molecule (VCAM)-1, intracellular adhesion molecule (ICAM)-1, and E-selectin (Figure 1). Mononuclear cells bind to endothelial cells via these adhesion molecules and migrate into the subendothelial space. This process is induced by several bio-reactive mediators, including monocyte chemotactic protein (MCP-1), which plays a prominent role. Since they are located on the vessel wall, the monocytes develop into macrophages, and while the LDL oxidizes, they differentiate into foam cells. This process is performed by acyl-coenzyme A [cholesterol acyltransferase-1 (ACAT-1)] in the macrophages, which catalyzes the formation of cholesterol esters. As a secondary event, the synthesis of nitric oxide by the enzyme endothelial nitric oxide synthase (eNOS) is decreased (Figure 1$).^{25}$

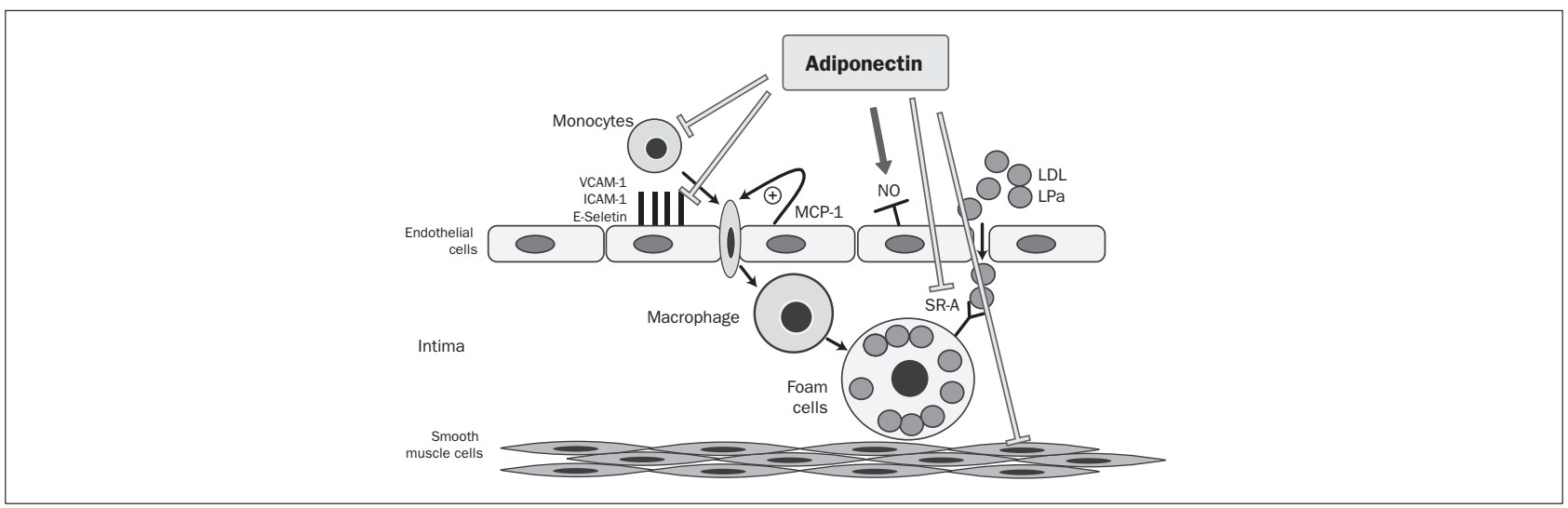

FIGURE 1 Adiponectin inhibits the up-regulation of adhesion molecules, the binding of monocytes to endothelial cells, the transformation of macrophages into foam cells and the proliferation and migration of vascular smooth muscle cells. In addition, the production of nitric oxide from endothelial cells is stimulated by this adipokine.

VCAM-1: Vascular cell adhesion molecules; ICAM-1: intracellular adhesion molecules. MCP-1: Attractive monocyte chemo protein; NO: nitric acid; LDL: low density lipoprotein; LPA: lipoprotein; SR-A: scanning receivers.

Source: Fasshauer et al., 2004.25 
The main role of adiponectin in vascular physiology is to modulate the cross-link between endothelial cells, smooth muscle cells, leukocytes, and platelets, and protect against vascular injury and atherogenesis. Atheroprotection is conferred by different actions of this protein, including anti-inflammatory effects, stimulation of nitric oxide production, mitigation of pro-atherogenic mediators and coronary plaque vulnerability modulation. ${ }^{26}$ Furthermore, in humans, plasma adiponectin levels are positively associated with arterial vasodilation in response to nitroglycerin (an endotheliumindependent vasodilation measure), which does not depend on insulin sensitivity. ${ }^{11}$

Adiponectin inhibits the production of proinflammatory cytokines and chemokines in endothelial cells, diminishing its ability to become activated in response to several inflammatory stimuli. Adiponectin also down-regulates receptor expression. The anti-inflammatory properties of adiponectin are mediated in part by activation of Adipor1 e Adipor2 receptors in monocytes, macrophages and endothelial cells, and lessen the accumulation of inflammatory cells at sites of vascular injury. ${ }^{27}$

A variety of substances that adversely affect the endothelial function are known, including free fatty acids, cytokines (such as TNF- $\alpha$ ), and pro-oxidant molecules, including oxidized low density lipoprotein (oxLDL). These mediators activate signaling kinases and are also closely related to the production of endothelial reactive oxygen species (ROS) (superoxide and $\mathrm{H}_{2} \mathrm{O}_{2}$ ), which play a key role in the development of atherogenesis in the context of metabolic syndrome and diabetes mellitus. ${ }^{27}$ Recent evidence also suggests that adiponectin potently inhibits the vascular endothelial growth factor (VEGF), which is induced by the formation of ROS, suggesting a broad anti-oxidant effect of adiponectin on blood vessels. ${ }^{4}$

In summary, adiponectin emerges playing a key role in the protection and integrity of vasculature. Decreased adiponectin levels (and therefore its function), for instance in the case of obesity and metabolic syndrome, make people more susceptible to atherosclerotic vascular disease. ${ }^{5}$

\section{INFLUENCE OF OBESITY ON ADIPONECTIN AND IN- SULIN RESISTANCE}

The term "diabesity" is used for diabetes occurring in the context of obesity. The overall prevalence of diabetes in 2010 was 284 million people worldwide, which is about $6.4 \%$ of world population, above what was projected in previous studies. In addition, projections for 2030 show that the prevalence may reach 439 million people, i.e. $7.7 \%$ of world population. The burden of diabetes on the global economy has increased in the past decade, reaching
376,000 million US dollars in 2010 , and is expected to total 490,000 million dollars in $2030 .{ }^{28}$

Insulin resistance has a genetic component not yet completely understood, which is often transmitted across generations. Moreover, obesity also has an important genetic component that invariably exacerbates insulin resistance. Thus, obesity and insulin resistance are usually present for many years before the appearance of other changes such as high blood pressure, dyslipidemia, T2DM and cardiovascular disease. ${ }^{5,27}$ Not all people with insulin resistance have all components associated with insulin resistance syndrome or syndrome $\mathrm{X}$, such as T2DM/ impaired glucose tolerance, HBP, dyslipidemia, microalbuminuria, obesity, hyperuricemia, sensitivity to sodium, and more. Therefore, it is likely that there is genetic predisposition to develop the syndrome. ${ }^{28,29}$

As noted above, insulin resistance is often associated with increased body weight and cardiovascular dysfunction. In addition, various adipokines such as adiponectin, TNF- $\alpha$, resistin and interleukins, are associated with this disease state. ${ }^{29}$

The first article indicating that adiponectin actively affects insulin sensitivity was published in 2001. A fragment of the C-terminal globular adiponectin is capable of reducing plasma glucose concentrations by increasing fatty acid oxidation in muscle (Figure 2)..$^{25,30,31}$

The Adipor1 receptor is predominantly found in skeletal muscle. Most studies have used globular adiponectin binding, which seems to have increased biological activity in skeletal muscle compared to the full-length form of the protein. The in vivo physiological significance of the globular isoform remains unclear, since the vast majority of circulating adiponectin is in full-length form. ${ }^{5,9,29}$

Globular adiponectin appears to work, at least in part, combined with AMP-activated protein kinase (AMPK) (and subsequently by inhibiting acetyl-CoA carboxylase) and PPAR- $\alpha$ (peroxisome proliferator-activated receptor alpha) in order to produce its metabolic effect in the muscles. AMPK phosphorylation in $\mathrm{C} 2 \mathrm{C} 12$ myotubes can be prevented by ceramidase inactivation, again indicating a role for sphingolipid metabolism with adiponectin signaling in this tissue. Adiponectin binding results in increased glucose uptake (through GLUT4 translocation) and non-oxidative glycolysis, while reducing the content of intramyocellular triacylglycerols and promoting oxidation of fatty acids. Furthermore, adiponectin has an effect on the number of mitochondria and types of oxidative fibers. ${ }^{30,32}$

In disease states, the effects of adiponectin in skeletal muscles are reduced. The binding of globular adiponectin and full-length adiponectin is reduced in obese rats and in 


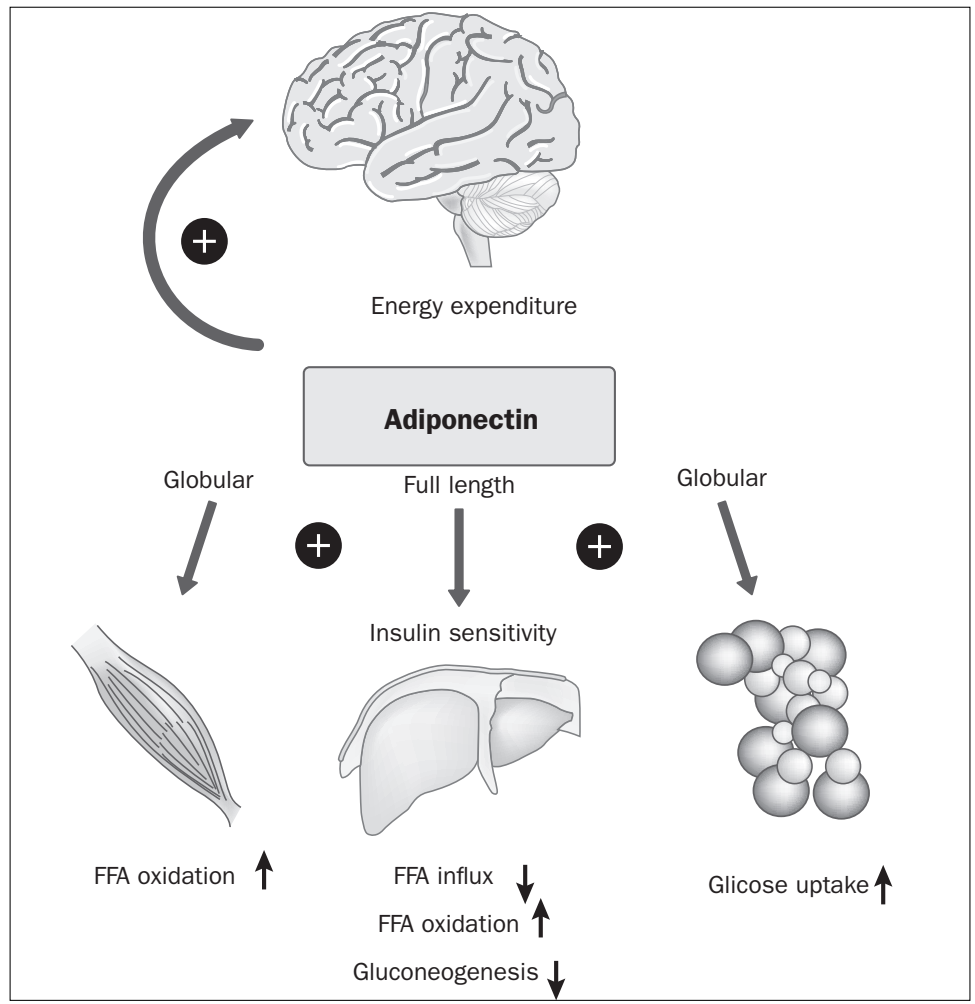

FIGURE 2 Hypothetical model for adiponectin action on insulin sensitivity and energy expenditure.

FFA: free fatty acids

Source: Fasshauer et al., 2004.25

insulin-resistant rats, which may be due to a lower density of adiponectin receptors. However, studies in humans did not show altered levels of Adipor1/Adipor2 RNAm associated with insulin resistance states. Myotubes in cultures from obese patients, with and without diabetes, reveal that impaired adiponectin stimulates the phosphorylation of AMPK and fatty acid oxidation, suggesting that adiponectin deficiency impairs the action of the receptor. These effects can be seen in in vitro samples of patients that are independent of other potentially confounding circulating hormonal factors (e.g., insulin levels). 33,34

Although there is a considerable number of works devoted to the action of adiponectin, the authors remain somewhat skeptical about the relevance of the publication of data related to the protein's physiology in vivo. The vast majority of studies focused on in vitro or in vivo studies were mostly performed with globular adiponectin., ${ }^{5,929}$

\section{TreatMEnT StRategies}

Despite the existing data being opposite in relation to the use of adiponectin as a clinically relevant biomarker, this adipokine is an insulin-sensitizing molecule, as well as anti-atherogenic. Therefore, therapeutic strategies directed at bioavailability of adiponectin are likely to have a significant beneficial effect on atherogenesis. These strategies should be focused on the regulation of adiponectin expression (and/or its receptors), or on adiponectin receptor segmentation, through the development of agonists. For example, the effect of insulin and insulin resistance on the specific inflammatory response of fatty tissue is a growing area of research. Insulin sensitizers thiazolidinediones, which are PPAR- $\gamma$ (peroxisome proliferator-activated receptor gamma) agonist and widely used in the treatment of T2DM, increase circulating adiponectin levels in humans. ${ }^{35}$

Another interesting class of drugs extensively used in the fields of cardiology and also related to adiponectin is angiotensin receptor type 1 blockers (ARB family). It has been shown that some agents belonging to the ARB family, such as telmisartan and, to a lesser degree, candesartan, act modulating PPAR $\gamma$ receptors. ${ }^{35}$ Takagi e Umemoto, ${ }^{36}$ in a meta-analysis, suggest that telmisartan therapy can increase adiponectin levels by $16 \%$ over other ARB therapies in patients without restriction, which proved to be robust in sensitivity analyzes. However, the main limitation of the study is heterogeneity in terms of follow-up time (3-12 months) and baseline insulin sensitiv- 
ity in patients with high blood pressure (hypertension without glucose tolerance, with poor glycemic control) in the included trials. We found that, based on meta-regression analysis, the longer the follow-up (therapy) duration is or the more impaired the insulin sensitivity is, the more effective in the increase of adionectin levels telmisartan compared with other ARB therapy is. Most trials included used a relatively small sample size (less than 100 patients). To confirm the results, a large randomized trial with telmisartan, including only patients with impaired glucose tolerance or diabetes, and with longer follow-up time (minimum 12 months) would be required. ${ }^{36}$

Other therapeutic strategies include the use of cannabinoid 1 receptor inverse agonists, such as taranabant, which can be particularly useful in the treatment of obesity. Recent studies show that the blockers of cannabinoid receptor type 1 , in addition to improving cardiometabolic risk factors also regulate adiponectin levels in vivo. ${ }^{37} \mathrm{How}-$ ever, the use of these drugs is essentially limited by serious side effects on the central nervous system and their clinical value is being reassessed. Last, up-regulation of adiponectin receptors and the use of adiponectin receptor agonists may also prove to be of clinical value in the future. ${ }^{38}$

\section{Prospects}

Adiponectin is a target for future research to reduce morbidity and mortality from atherosclerotic disease. ${ }^{2}$ Diet, exercise, cardiovascular drugs and insulin sensitizers improve endothelium-dependent vascular function, increase adiponectin levels, and decrease inflammation and insulin resistance through different mechanisms (Figure 3). $8,9,37$

These integrated mechanisms would help to explain the beneficial effects of combination therapy in recent clinical trials. Thus, there is no scientific justification to recommend a combination of lifestyle changes and multiple drugs, belonging to separate classes, to prevent atherosclerosis and coronary heart disease. In therapeutic interventions aimed at adiponectin, evidence suggests that the combination of inflammatory signaling pathways and insulin signaling pathways cause metabolic insulin resistance and endothelial dysfunction that synergistically predispose to cardiovascular disease in metabolic syndrome (Figure 3). Prospective studies are needed to examine the possibility of increasing adiponectin levels in the context of insulin sensitivity, to improve primary outcomes, including the incidence of diabetes mellitus and cardiovascular events. ${ }^{39}$

However, there are some other paradoxical points involving adiponectin. Despite the well-established role of proinflammatory cytokines, e.g. TNF- $\alpha$ and IL-6, in heart failure, the potential impact of adiponectin in the pathophysiology of this condition is largely controversial. Very recently pub-

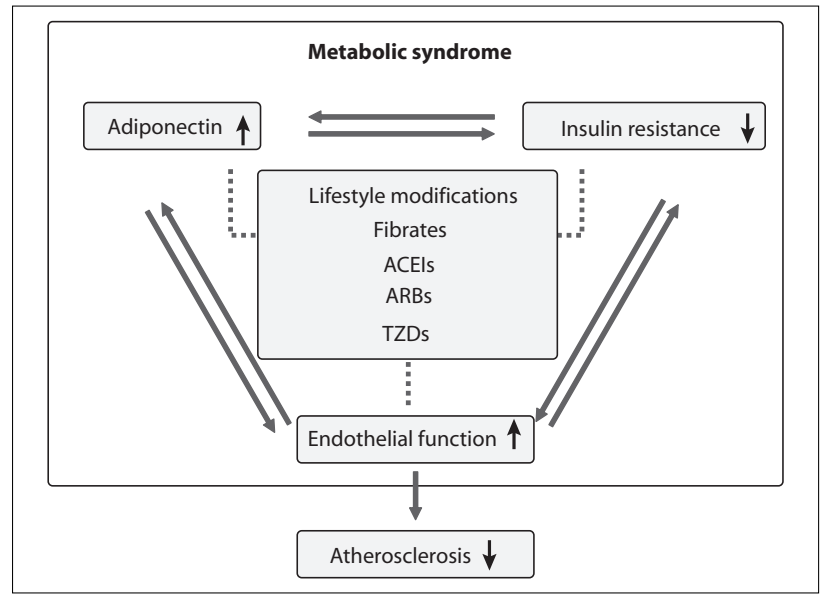

FIGURA 3 Therapeutic intervention mechanisms of adiponectin, insulin resistance and endothelial function. Lifestyle modifications and cardiovascular drugs such as fenofibrate, Angiotensin-converting enzyme (ACE) inhibitors, angiotensin II type 1 receptor blockers (ARBs), and thiazolidinediones (TZDs) increase plasma adiponectin levels, reduce insulin resistance, and improve endothelial function. These may be mechanisms to reduce cardiovascular disease. Source: Han et al./Journal of the American College of Cardiology Vol.49, No.5, 2007. ${ }^{5}$

lished data suggest that adiponectin levels are increased in patients with chronic heart failure. In fact, adiponectin levels are positively correlated with the levels of brain natriuretic peptide and the severity of ventricular dysfunction estimated according to the New York Heart Association (NYHA). ${ }^{40,41}$ Moreover, it is suggested that adiponectin predisposes mortality and morbidity in patients with heart failure. ${ }^{42}$

Considering the vasoprotective and cardioprotective properties of adiponectin, the results above are easily explained. Cachexia appears to be a link, since reduction in body weight can regulate the synthesis of adiponectin. High levels of adiponectin may simply reflect the hyper-catabolic state in severe heart failure. ${ }^{40} \mathrm{McEntegart}$ et $\mathrm{al} .{ }^{43}$ have recently shown that adiponectin levels are increased in patients with heart failure in the presence of cachexia. Therefore, it is necessary to clarify whether increased levels of adiponectin may be involved in the pathogenesis of heart failure or if they simply reflect the degree of cachexia in these patients. ${ }^{43}$

Recombinant adiponectin may have a beneficial role in the therapeutic treatment and prevention of cardiovascular diseases in the future. ${ }^{9,29,39}$

\section{Conclusion}

Adiponectin is a key adipokine, which participates in many metabolic activities and its levels are reduced in obese people. This increases the risk of developing insulin resistance and cardiovascular disease due to the molecule's regulatory role in the organism. 
Of the three soluble forms of adiponectin, the high molecular weight multimer seems to be the most important biological role. At the cellular level, adiponectin increases the bioavailability of endothelial nitric oxide and has anti-inflammatory, anti-apoptotic and anti-atherogenic properties.

Adiponectin is a key mediator of systemic insulin sensitivity and glucose homeostasis. These effects are achieved through a diverse range of important targets, including liver, pancreas, cardiac myocytes and immune system, and the adipose tissue itself. The main metabolic effects of adiponectin are suppression of hepatic glucose production and modulation of suppressing inflammatory responses in other cell types, including macrophages. Moreover, through its action on sphingolipid pathways, it has potent anti-apoptotic action, which has been particularly documented in the case of beta cells and cardiac myocytes.

Despite the beneficial role of adiponectin on vascular homeostasis, studies suggest that increased levels of circulating adiponectin are associated with increased cardiovascular mortality in patients with coronary artery disease. In addition, hypoadiponectinemia has been paradoxically associated with better clinical outcomes in patients with severe heart failure, but this finding is likely to reflect an association with the increased hypercatabolic state observed in these patients.

It is too soon to say that adiponectin can be used as a therapeutic target in cardiovascular disease, and more research is needed to understand the complexity of the molecular mechanisms that regulate adiponectin biosynthesis and the molecule's actual contribution to cardiovascular homeostasis.

\section{Resumo}

Relação entre adiponectina, obesidade e resistência à insulina.

Objetivos: as condições de obesidade e sobrepeso representam um grande risco para uma série de comorbidades, incluindo as síndromes clínicas decorrentes da doença aterosclerótica. Recentes estudos indicam fortemente que o tecido adiposo é um órgão endócrino ativo que secreta fatores bioativos, como as adipocinas. A adiponectina parece ter um papel regulador no mecanismo da resistência à insulina e no desenvolvimento da aterosclerose. Este estudo de revisão tem como objetivo avaliar os efeitos antiaterogênicos da adiponectina e suas propriedades para melhorar e reproduzir ações metabólicas e vasculares de insulina e sua influência na função endotelial.

Métodos: revisão qualitativa, exploratória e bibliográfica foi realizada nas bases de dados PubMed, Portal Capes e Scielo utilizando os unitermos "adiponectin", "obe- sity", "insulin resistance", "anti-inflammatory", "therapeutic strategies" e "future prospects".

Resultados: evidências sugerem que a adiponectina tem propriedades antiaterogênicas com efeitos anti-inflamatórios sobre a parede vascular. Além disso, modifica a sinalização vascular intracelular e exerce efeitos antioxidantes indiretos sobre o miocárdio humano. Por outro lado, existem estudos que sugerem que níveis aumentados de adiponectina são paradoxalmente associados com pior prognóstico na síndrome de insuficiência cardíaca, embora os mecanismos ainda não estejam claros.

Conclusão: é incerto se os níveis de adiponectina têm algum significado clínico para a estratificação de risco na doença cardiovascular ou se simplesmente refletem a ativação dos mecanismos complexos subjacentes. Modificações de estilo de vida e alguns tratamentos medicamentosos para hipertensão e doenças coronarianas têm tido efeitos importantes para aumentar os níveis de adiponectina e, simultaneamente, diminuir a resistência à insulina e a disfunção endotelial.

Palavras-chave: obesidade, adiponectina, resistência à insulina.

\section{References}

1. Costa MC, Brito LL, Barbosa PJB, Ines L. Adiponectina e baixo risco cardiometabólico em obesas. Arq Bras Endocrinol Metab. 2011;2(004-2730):55.

2. Pelajo CF, Lopez-Benitez JM, Miller LC. Obesity and disease activity in juvenile idiopathic arthritis. Pediatr Rheumatol Online J. 2012;10(1):3.

3. Olsovsky J. Obesity and diabetes. Vnitr Lek. 2003;49(12):956-9.

4. Kuo SM, Halpern MM. Lack of association between body mass index and plasma adiponectin levels in healthy adults. Int J Obes (Lond). 2011; 35(12):1487-94.

5. Han SH, Quon MJ, Kim JA, Koh KK. Adiponectin and cardiovascular disease: response to therapeutic interventions. J Am Coll Cardiol. 2007;49(5):531-8.

6. Antoniades C, Antonopoulos AS, Tousoulis D, Stefanadis C. Adiponectin: from obesity to cardiovascular disease. Obes Rev. 2009;10(3):269-79.

7. Filho RFF, Mariosa LS, Ferreira SRG, Zanella MT. Gordura visceral e síndrome metabólica: mais que uma simples associação. Arq Bras Endocrinol Metab. 2006;50(2)(0004-2730):230-38.

8. Frystyk J, Berne C, Berglund L, Jensevik K, Flyvbjerg A, Zethelius B. Serum adiponectin is a predictor of coronary heart disease: a population-based 10-year follow-up study in elderly men. J Clin Endocrinol Metab. 2007;92(2):571-6.

9. Turer AT, Scherer PE. Adiponectin: mechanistic insights and clinical implications. Diabetologia. 2012;55(9):2319-26.

10. Peterlin BL, Alexander G, Tabby D, Reichenberger E. Oligomerization statedependent elevations of adiponectin in chronic daily headache. Neurology. 2008;70(20):1905-11.

11. Vaiopoulos AG, Marinou K, Christodoulides C, Koutsilieris M. The role of adiponectin in human vascular physiology. Int J Cardiol. 2012;155(2):188-93.

12. Bruun JM, Lihn AS, Verdich C, Pedersen SB, Toubro S, Astrup A, et al. Regulation of adiponectin by adipose tissue-derived cytokines: in vivo and in vitro investigations in humans. Am J Physiol Endocrinol Metab. 2003;285(3):E527-33.

13. Yamauchi T, Nio Y, Maki T, Kobayashi M, Takazawa T, Iwabu M, et al. Targeted disruption of AdipoR1 and AdipoR2 causes abrogation of adiponectin binding and metabolic actions. Nat Med. 2007;13(3):332-9.

14. Awazawa M, Ueki K, Inabe K, Yamauchi T, Kubota N, Kaneko K, et al. Adiponectin enhances insulin sensitivity by increasing hepatic IRS-2 expression via a macrophage-derived IL-6-dependent pathway. Cell Metab. 2011;13(4):401-12.

15. Fu Y, Luo N, Klein RL, Garvey WT. Adiponectin promotes adipocyte differentiation, insulin sensitivity, and lipid accumulation. J Lipid Res. 2005;46(7):1369-79. 
16. Lara-Castro C, Fu Y, Chung BH, Garvey WT. Adiponectin and the metabolic syndrome: mechanisms mediating risk for metabolic and cardiovascular disease. Curr Opin Lipidol. 2007;18(3):263-70.

17. Sell H, Dietze-Schroeder D, Eckardt K, Eckel J. Cytokine secretion by human adipocytes is differentially regulated by adiponectin, AICAR, and troglitazone. Biochem Biophys Res Commun. 2006;343(3):700-6

18. Stefan N, Vozarova B, Funahashi T, Matsuzawa Y, Weyer C, Lindsay RS, et al. Plasma adiponectin concentration is associated with skeletal muscle insulin receptor tyrosine phosphorylation, and low plasma concentration precedes a decrease in whole-body insulin sensitivity in humans. Diabetes. 2002;51(6):1884-8.

19. Bacha F, Saad R, Gungor N, Arslanian SA. Adiponectin in youth: relationship to visceral adiposity, insulin sensitivity, and beta-cell function. Diabetes Care. 2004;27(2):547-52.

20. Caballero AE. Endothelial dysfunction in obesity and insulin resistance: a road to diabetes and heart disease. Obesity Res. 2003;11(11):1278-89.

21. Carvalho MHC, Colaço AL, Fortes ZB. Citocinas, Disfunção Endotelial e Resistência à Insulina. Arq Bras Endocrinol Metab. 2006;50(2)(0004-2730):45

22. ORourke RW, Metcalf MD, White AE, Madala A, Winters BR, Maizlin, II, et al. Depot-specific differences in inflammatory mediators and a role for NK cells and IFN-gamma in inflammation in human adipose tissue. Int J Obes (Lond). 2009;33(9):978-90.

23. Gerhardt CC, Romero IA, Cancello R, Camoin L, Strosberg AD. Chemokines control fat accumulation and leptin secretion by cultured human adipocytes. Mol Cell Endocrinol. 2001;175(1-2):81-92.

24. Osborn O, Olefsky JM. The cellular and signaling networks linking the immune system and metabolism in disease. Nat Med. 2012;18(3):363-74

25. Fasshauer M, Paschke R, Stumvoll M. Adiponectin, obesity, and cardiovascular disease. Biochimie. 2004;86(11):779-84.

26. Sprague AH, Khalil RA. Inflammatory cytokines in vascular dysfunction and vascular disease. Biochem Pharmacol. 2009;78(6):539-52.

27. Hopkins TA, Ouchi N, Shibata R, Walsh K. Adiponectin actions in the cardiovascular system. Cardiovasc Res. 2007;74(1):11-8.

28. Farag YM, Gaballa MR. Diabesity: an overview of a rising epidemic. Nephrol Dial Transplant. 2011;26(1):28-35.

29. Iwabu M, Yamauchi T, Okada-Iwabu M, Sato K, Nakagawa T, Funata M, et al. Adiponectin and AdipoR1 regulate PGC-1alpha and mitochondria by $\mathrm{Ca}(2)$ and AMPK/SIRT1. Nature. 2010;464(7293):1313-9.

30. Sharma K. The link between obesity and albuminuria: adiponectin and podocyte dysfunction. Kidney Int. 2009;76(2):145-8.

31. Cavusoglu E, Ruwende C, Chopra V, Yanamadala S, Eng C, Clark LT, et al. Adiponectin is an independent predictor of all-cause mortality, cardiac mortality, and myocardial infarction in patients presenting with chest pain. Eur Heart J. 2006;27(19):2300-9.
32. Holland WL, Miller RA, Wang ZV, Sun K, Barth BM, Bui HH, et al. Receptormediated activation of ceramidase activity initiates the pleiotropic actions of adiponectin. Nat Med. 2011;17(1):55-63.

33. Chen MB, McAinch AJ, Macaulay SL, Castelli LA, OBrien P E, Dixon JB, et al. Impaired activation of AMP-kinase and fatty acid oxidation by globular adiponectin in cultured human skeletal muscle of obese type 2 diabetics. J Clin Endocrinol Metab. 2005;90(6):3665-72.

34. Debard C, Laville M, Berbe V, Loizon E, Guillet C, Morio-Liondore B, et al Expression of key genes of fatty acid oxidation, including adiponectin receptors, in skeletal muscle of Type 2 diabetic patients. Diabetologia. 2004;47(5):917-25.

35. Li W, Tonelli J, Kishore P, Owen R, Goodman E, Scherer PE, et al. Insulinsensitizing effects of thiazolidinediones are not linked to adiponectin receptor expression in human fat or muscle. Am J Physiol Endocrinol Metab. 2007;292(5):E1301-7

36. Takagi H, Umemoto $\mathrm{T}$. Telmisartan increases adiponectin levels: a metaanalysis and meta-regression of randomized head-to-head trials. Int J Cardiol. 2012;155(3):448-51.

37. Viveros MP, de Fonseca FR, Bermudez-Silva FJ, McPartland JM. Critical role of the endocannabinoid system in the regulation of food intake and energy metabolism, with phylogenetic, developmental, and pathophysiological implications. Endocr Metab Immune Disord Drug Targets. 2008;8(3):220-30.

38. Oh DK, Ciaraldi T, Henry RR. Adiponectin in health and disease. Diabetes Obes Metab. 2007;9(3):282-9.

39. Kim JA, Montagnani M, Koh KK, Quon MJ. Reciprocal relationships between insulin resistance and endothelial dysfunction: molecular and pathophysiological mechanisms. Circulation. 2006;113(15):1888-904.

40. Tentolouris C, Tousoulis D, Antoniades C, Bosinakou E, Kotsopoulou M, Trikas A, et al. Endothelial function and proinflammatory cytokines in patients with ischemic heart disease and dilated cardiomyopathy. Int J Cardiol. 2004;94(2-3):301-5

41. Nakamura T, Funayama H, Kubo N, Yasu T, Kawakami M, Saito M, et al. Association of hyperadiponectinemia with severity of ventricular dysfunction in congestive heart failure. Circ J. 2006;70(12):1557-62.

42. George J, Patal S, Wexler D, Sharabi Y, Peleg E, Kamari Y, et al. Circulating adiponectin concentrations in patients with congestive heart failure. Heart. 2006;92(10):1420-4.

43. McEntegart MB, Awede B, Petrie MC, Sattar N, Dunn FG, MacFarlane NG, et al. Increase in serum adiponectin concentration in patients with heart failure and cachexia: relationship with leptin, other cytokines, and B-type natriuretic peptide. Eur Heart J. 2007;28(7):829-35 